\title{
The Spectre of Uncertainty in Communicating Technological Risk
}

\author{
Michael T. Brösius \\ (M.A. Dissertation)
}

December 1993 


\section{DISCLAIMER}

This document was prepared as an account of work sponsored by an agency of the United States Government. Neither the United States Government nor the University of California nor any of their employees, makes any warranty, express or implied, or assumes any legal liability or responsibility for the accuracy, completeness, or usefulness of any information, apparatus, product, or process disclosed, or represents that its use would not infringe privately owned rights. Reference herein to any specific commercial products, process, or service by trade name, trademark, manufacturer, or otherwise, does not necessarily con titute or imply its endorsement, recommendation, or favoring by the United States Government or the University of Californis. The views and opinions of authors expressed herein do not necessarily state or reflect those of the United Stat.s Government or the University of California, and shall not be used for advertising or product endorsement purposes.

This report has been reproduced directly from the best available copy.

Available to DOE and DOE contractors from the Office of Scientific and Technical Information P.O. Box 62, Oak Ridge, TN 37831

Prices available from (615) 576-8401, FTS 626-8401

Available to the public from the

National Technical Information Service

U.S. Department of Commerce 5285 Port Royal Rd, Springfield, VA 2216

Work performed under the auspices of the U.S. Department of Energy by Lawrence Livermore National Laboratory under Contract W-7405-Eng-48. 
The Spectre of Uncertainty

\title{
in Communicating Technological Risk
}

\author{
Michael T. Brösius \\ (M.A. Dissertation)
}

December 1993

Lawrence Livermore National Laboratory University of California • Livermore, California • 94551 


\section{The Spectre of Uncertainty in Communicating Technological Risk}

\section{Introduction}

Every process, whether natural or technological, in which resources are transferred from one system to another carries some potential for risk to the environment or to organisms that dwell within it. Beginning with the discovery of fire, societies have investigated new ways to make life safer and more comfortable. This investigation, which we call science, and the resulting discoveries, technology, have succeeded in reducing many of the risks that humans have struggled to overcome. Gunpowder, for example, significantly reduced the hunter's risk of becoming his prey's meal; railroad technology diminished the traveler's risk by reducing cross-couniry travel time from several months to a few days. Both technologies, however, introduced elements of risk to their users and to the environment. As we approach the 21st century, some of the greatest risks humankind faces will arise from the failures of technology.

Some element of technological risk exists at nearly every level of human activity. Meaningful communication between technology sponsors and the public at risk must occur continuously at every level of interaction-locally and internationally - to achieve comfort and safety levels amenable both to technology and the continuation of life on our planet.

Ironically, scientists have not been successful in accurately predicting and quantifying the actual risks associated with advancing technology. In fact, as we 
learn more about the world around us and exploit its resources in the name of technology, the relation between benefit and risk becomes more obscure. Because the methodologies employed to ascertain benefit-to-risk ratios are for the most part uncertain, the results can only be inferred in terms of science's best guess.

Technology sponsors and technical communicators, therefore, faced with the spectre of risk assessment as a crapshoot (at best), must abandon the notion of science as infallible, suspend assumptions of the reliability of the results of scientific inquiry, and confront this vast uncertainty with well-developed moral and ethical value systems.

\section{Objectives}

The original goal of this thesis project was to conduct a study of the emerging field of risk communication to determine the state of the art in terms of applicability of concepts and processes to professional technical communicators, and to propose a set of guidelines for technology sponsors and writers, based on my synthesis of the information. After reviewing approximately 30 recent journal articles, attending a risk communication workshop at the University of California at Davis, and a seminar on risk communication at the Institute of Electrical and Electronic Engineers (IEEE) Association annual International Professional Communicators' Conference (IPCC) in Santa Fe, New Mexico, I realized that the concept of risk communication extends almost infinitely into closely associated fields such as cognitive and behavioral psychology, human factors engineering, health and safety legislation, and actuarial and statistical analysis. It soon became apparent that to be effective, my study would need to focus on a limited 
perspective of the field. After reviewing more than two hundred journal articles and a dozen books written within the last ten years on various aspects of risk communication, I concluded that the majority of the literature focused on theoretical and anecdotal issues; although an abundance of do-and-don't lists and descriptions of successful and failed attempts at risk communication existed, there seemed to be no connection between theory and real-world application. A prospective risk communicator might find a checklist of right and wrong approaches-most of the literature is in general agreement, in theory, that some strategies work better than others. Technology sponsors can find volumes of published material that compares the potential conflict of interest between risk makers and risk takers. The literature does not clearly describe, however, the potential moral and ethical conflicts that can exist between technology sponsors and the technical communicators whose job it is to present potentially risky technology to the non-technical people most likely to be imperiled by such risk. Equally important, the literature does not address the issue of uncertainty-not the uncertainty likely to be experienced by the community at risk, but the unreliable processes and methodologies used by technology sponsors to define, quantify, and develop strategies to mitigate technological risks.

In this paper, therefore, I intend to go beyond a description of risk communication, the nature of the generally predictable interaction between technology advocates and non-technically trained individuals, and current trends in the field. Although that kind of information is critical to the success of any risk communication activity, and I have included it when necessary to 
provide background and perspective, without knowing how and why risk assessment is done, it has limited practical applicability outside the sterile, valuefree vacuum in which it is usually framed. Technical communicators, particularly those responsible for communicating potential technological risk, must also understand the social, political, economic, statistical, and ethical issues they will invariably encounter.

\section{Definitions}

Risk commurication is the interactive process of exchanging information and opinions among individuals, groups, and institutions concerning a risk or potential risk to human health or to the environment. It is an emerging system of communicating with potentially hostile audiences about sensitive environmental, safety, and health issues they face. Risk communication is a growing specialty field in communication that draws from well-established principles of sociology and psychology. Frank Baker defines risk as "the quantification of a hazard in terms of the probability that harm or undesired consequences will be realized." But the mathematical representation of probability alone is not enough to instill public confidence in technology sponsors' projects and products. On the contrary, such statistics often provoke disbelief and distrust. Risk assessors traditionally have defined risk as magnitude $\times$ probability (Baker). A simplified example describes a hiker at risk of being seriously wounded by a venomous snake. This risk depends on two things: the number of snakes in the area (probability) and how lethal the snakes' venom is (magnitude). The greater the 
number of snakes and the greater the potency of the snakes' venom, the greater the risk of a serious injury to the hiker (Gardner).

According to Peter M. Sandman, a well-known expert on risk assessment communication, "Risk is the sum of hazard and outrage. The public pays too little attention to science, and the experts pay absolutely no attention to outrage." Outrage results from the subjective, non-scientific factors that influence a person's perception of a risk. The risk assessment formula is then revised:

$$
\text { Risk }=(\text { magnitude } \times \text { probability })+\text { outrage } .
$$

In the hypothetical case described above, the hiker's perception of risk may be far greater than the actual risk, depending on individual fear or loathing of snakes. The "outrage factor" often governs a lay person's perception of risk. One important outrage factor is whether the risk is voluntary or involuntary; whether it is chosen by the person or imposed by an outside source. It is important for technology sponsors and risk communicators to address the audience's potential for outrage as well as the scientific aspects of risk. For the purposes of risk communication, perceived risks are just as valid as actual (statistically derived) risks, and may have more bearing on the audience's behavior and willingness to accept risk.

Two other definitions are helpful in undersianding the process of risk communication. Risk assessment is the field of study concerned with analyzing the possibility of hazards uccurring and the potential damage they can cause. Risk management is the field of study in which decision makers use risk assessments to decide how to mitigate the consequences of the risk. 


\section{Background}

Recent legislation regarding right-to-know activities and emergency response planning requires industry to develop and disseminate information about the immediate risks associated with incidents such as fires and explosions, as well as certain long-term risks, such as cancer, that are associated with prolonged exposure to chemical emissions and other potential technological hazards. In order to understand and improve the communication process, it is critical to identify the current attitudes of technology sponsors and communities toward risk-particularly when differences in attitudes may impede effective risk management. Technology sponsors must be able to answer, truthfully, difficult questions related to risk perception and risk acceptability. For example, how do communities perceive the risks presented by neighboring industries? How do a company's communication endeavors influence these perceptions? Do companies' attempts at communicating work well, or is it better to remain silent?

Although the designers and operators of industrial facilities generally have the technical expertise to identify potential hazards and attempt to analyze and quantify the risks posed by their operations, they often find it difficult to communicate this knowledge to employees and to the general public in a constructive and credible manner. Risk quantification is a complex process; usually risk levels can be estimated only within orders of magnitude. Most people are uncomfortable with such a high degree of uncertainty and are often distrustful of such estimates. Moreover, the perception of risk and the 
determination of its acceptability are influenced by many factors that are not related to the actual risk level or that are beyond industry's understanding or control. Therefore, improvements in risk communication may not change public attitudes toward technological risks. The process of communicating risk to the public is significantly more complex than other types of scientific and technical communication; a skillful risk communicator should be able to handle any technical communication task with relative ease. Risks to the public's health and safety and to our natural resources must be communicated to an often hostile and frightened public, a task that involves many people in many roles, including technical communicators.

In this confused and sometimes confrontational atmosphere, improving the lines of risk communication can only be beneficial. Legislation has spurred new risk communication efforts that involve all parties-technology sponsors, the public, regulatory agencies, and community response personnel. The principal components of risk communication-audience analysis, perception of risk, honest and open discourse, and rational risk comparison-are applied to the interaction between two parties (usually technology sponsors and the public at risk). Risk communication is regarded as successful if those involved feel that they are adequately informed. Risk communication does not intend to manipulate the audience to make a certain decision, but rather to provide people with the information they need to make informed choices about the possible risks they face. Improved communication will result in more effective emergency 
planning, which has benefits not only in the face of industrial emergencies but also in response to natural disasters.

The areas of technology that are most likely to result in the need for risk communication are: policy choice-choosing a principle upon which technology development will be based; plant or product development-the implementation of a specific technology; hazard avoidance-actions taken to reduce, avert, or prepare for hazards resulting from existing technology, natural phenomena, or technological products; and accident management-initiating action when potential hazards have been identified (Cannel).

\section{The Necessity of Disclosure}

In 1958, a book commonly used to train industrial hygienists and toxicologists specifically advised against disclosing to workers that hazardous materials were present in a work environment. Occupational health and safety professionals now recognize their ethical and legal responsibilities to disclose risks, but the methods used to evaluate such risks are unreliable and the processes of communicating them are developing slowly and painfully (Cohen, et al.).

The U.S. Department of Defense recently approved the use of "depleted" uranium in the manufacture of armor-piercing shells and tank armor. This material is extremely dense, plentiful, and at first glance an apparent good choice for military applications. Unfortunately, the radioactive nature of this so-called depleted material was not as well understood by military strategists as we might assume. Depleted uranium is a by-product of the process used to enrich uranium 
for use in reactors and weapons. Although the fissionable U-238 has been extracted, it remains about half as radioactive as natural uranium; it continues to ionize and remains toxic for many years (Milwaukee Journal). Without warning or training in how to handle it, U.S. soldiers were exposed to radioactivity from this material during Operation Desert Storm. Consequently, many who may have been exposed to low-level radiation are now reporting post-exposure medical problems and genetic defects.

The results of a recent study conducted by Mort Mendelsohn, a noted U.S. biomedical scientist and director of the Hiroshima Institute, appeared in the journal Radiation Quarterly. The article presents new evidence-contrary to what has been taught by experts for decades-that there is no "safe" level of exposure to radiation. According to the study, even infrequent, low-level diagnostic $x$ rays can cause irreparable cell and chromosomal damage. How can we be certain that this new information is reliable? We cannot.

\section{More Recent Examples}

Risky technology is not confined to recombinant-genetics laboratories, dismantling nuclear weapons, and high-tech battlefields. Occupational injuries resulting from repetitive motion syndrome are approaching epidemic levels despite employers' attempts to provide ergonomically correct work environments. One hundred thousand workers die each year from occupational illness; nearly a half-million new cases of work-related disease are reported each year. Three thousand truckloads of spent reactor fuel is hauled to high-level radioactive waste sites every year (Freudenberg). 
Between 1940 and 1980, the production of synthetic organic compounds increased from less than 10 billion pounds per year to more than 350 billion pounds per year. The EPA estimates there are 70,000 chemicals already in use around the world; each year, one thousand new compounds are introduced. Only about $70 \%$ of these have been classified in terms of their toxicity (Freudenberg).

A recent University of California (UC) Berkeley study reports that California allows the use of pesticides that poison thousands of farm workers every year (Robinson). Although the state forbids the use of pesticides that have been proven to imperil consumers, it largely ignores those that harm farm workers. Because the farm workforce is generally transient, often undocumented, predominantly non-English-speaking, and usually non-voting, the issue escapes notice.

The UC study ranks the 70 most common pesticides in the state according to how much they are used and how dangerous they are to workers. It finds that only two out of the 70 have been fully evaluated and registered for use by the U. S. Environmental Protection Agency. In some cases, the state requires safeguards-such as using special equipment to mix the chemicals-but doesn't enforce them. Only about a quarter of the most hazardous pesticides are packaged with adequate warnings. The study also found that employers often do not provide adequate drinking water or bathrooms for workers who suffer acute pesticide exposure. Some send workers into the fields immediately after chemicals are sprayed. 
More than a thousand worker poisonings are documented every year because of unsafe chemicals or unsafe ways of using them. About four or five times as many cases are probably never identified or reported. Safe alternatives to pesticides have been developed for most crops in California, but most growers do not use them, partly because they are more expensive and partly because the growers are reluctant to try new products that could reduce their crop yield. The UC study recommends taxing the sale of the dangerous pesticides to encourage growers to switch to the safer products. Money from the tax would pay for farm worker protection and research into non-toxic products for agriculture.

The U.S. Department of Transportation classifies 1,600 materials "hazardous." More than 18,000 accidents are reported each year involving transportation of these hazardous materials. Tank cars containing carbon tetrachloride, arsenic, cadmium, chromium, nickel, trichloroethylene, trichloroethane, and others explode or leak. In the U.S. alone, 11 million gallons of gasoline leaks into the soil each year. People come into contact with these toxic chemicals most commonly by drinking contaminated water (Freudenberg).

Newspapers carry speculative articles nearly every day that warn of health and safety risks in our lives-from the naturally occurring radon in the soil beneath our homes; to the polychlorinated biphenyls (PCBs) used in floor coverings, to insulate houses, and to wrap food; to the possible risk of Alzheimer's Disease from using aluminum cookware in our kitchens; to miscarriages blamed on the electric blankets in our bedrooms. In Contra Costa 
County, California-the home of many oil refineries and chemical plants-the reported lung cancer rate is $40 \%$ higher than in neighboring communities.

\section{Electromagnetic Fields (EMF)}

Electromagnetic fields generated by electric hair dryers, razors, and other household appliances are linked to cancer, depression, and leukemia. Every time electricity runs through a wire or an appliance, it produces an electromagnetic field. Low magnetic fields that exist in every appliance plugged into an electrical outlet are considered harmless. But much stronger EMF are generated when the appliances are turned on. The strongest EMF, like $x$ rays and microwaves, can rearrange the content of cells and are "known to be harmful." These silent, invisible waves weaken with distance from their source. Depending on the study and sensitivity of the instruments used, exposures vary. Ambient EMF fields in most American homes is about 0.5 milligauss; activist experts set a safe limit at 2 milligauss. In one study, instruments measured 20 milligauss touching an electric blanket and 1,400 milligauss near an electric hair dryer (Howe). In a similar study, the hair dryer registered only 10 milligauss, and directly above a sidewalk plate marked "High Voltage" only 75 milligauss. How do we know which study is correct? The truth is that no one really knows.

Regardless of the numeric representations, epidemiological research is beginning to suggest an association between human exposure to EMF and statistically significant increases in leukemia and other cancers. A Boston University study shows that people who say they live near a high-voltage transmission line are twice as likely to have symptoms of depression as those 
who do not (Yakutchik). William Feero, an electrical engineer in State College, PA, who analyzes EMF says avoidance is "a question of resources, inclination, and situation." Feero is in the neutral middle of a raging debate between scientists who believe in EMF hazards and scientists who won't believe until they know how fields effect the body. Feero will not cross the street to avoid walking under a high voltage wire because he believes the greater risk is to be hit by a car while crossing the street. Some concerned individuals have spent thousands of dollars to have their homes rewired; others have taken huge losses in the real estate market to move away from a transformer substation.

The U. S. government spent more than \$65 million on EMF research in 1992. Because of convincing research done in Europe, the government of Sweden is considering setting magnetic field limits for new power lines at 2 milligauss. In New York and Florida, the only states that have set limits, the standards are 150 and 250 milligauss, respectively. The agonizing result of all this research is that no one really knows if EMF is extremely dangerous, a cause for some concern, or simply innocuous. Some experts recommend taking moderate precautions such as using a quilt instead of an electric blanket, and advise staying out of the way of microwave ovens and other higher voltage appliances when they are in use, but most believe there is no reason to worry until more facts are available. On the other extreme, researchers at the University of Texas believe that EMF is a serious hazard that interferes with the brain's pineal gland, suppressing the production of melatonin-a hormone known to protect against certain cancers. 
Deciding what is safe is not simple. The strength of the field might not be as important as whether you are moving in and out of different fields. That is the focus of much new research. The "official" word from the U.S. Environmental Protection Agency is that EMF is a "probable" carcinogen. "There is sufficient data to hypothesize there could be health effects" (Yakutchick).

\section{When Enough is Too Much}

In this era of information overload, it is difficult to distinguish genuine, proven hazards from speculative, potential dangers. A generation after the United States government began to respond to poisoned streams and unbreatheable air with the world's first comprehensive strategy to protect the environment, many scientists, economists, and government officials conclude that much of America's environmental effort has gone seriously awry (New York Times). These experts say that in the last fifteen years environmental policy has too often emerged largely in reaction to popular panics (perceived risk)-not in response to sound scientific analyses of which environmental hazards present the greatest risks. As a result, billions of dollars are wasted each year confronting problems that are no longer considered especially dangerous, leaving little money for others that are thought to be more harmful, or for investigating new or unknown hazards.

In the first wave of the modern environmental movement, starting about thirty years ago, the focus was on broad efforts to eliminate the most visible pollution pouring from smokestacks and sewer pipes-programs with clear goals that had obvious benefits. But a second wave began in the late 1970s, with 
a new strategy intended to limit visible pollution further, and to begin attacking invisible threats from toxic substances.

To that end, state and federal governments began writing sweeping environmental laws, some of which included strict regulations to ensure that certain toxic compounds were not present in air, water, or the ground at levels in excess of a few parts per billion-concentrations that could be measured with only the most sophisticated equipment. The result was a tangle of regulations that the EPA estimates costs more than $\$ 140$ billion a year-roughly $\$ 100$ billion spent by industry and $\$ 40$ billion by government. But what is now becoming apparent, some scientists and public health specialists say, is that many of these laws-written in reaction to popular concerns about toxic waste dumps or asbestos in the schools, for example-were based on little if any sound research about the true nature of the threat. Since 1980, literally thousands of regulations have been written to restrict compounds that had caused cancer in rats or mice, even though these animal studies often fail to predict how the compounds might affect humans.

With only rare exceptions, Congress has approved new laws without subjecting them to even rudimentary cost-benefit analyses. One reason is that during the 1980s, when the economy seemed healthier, there was far less pressure on Congress to consider the cost of environmental policy.

Now a new administration intent on strengthening environmental policy is in office at a time when competition for scarce financial resources is fierce. At the same time, critics claim that some of the nation's environmental protection efforts 
are excessively costly-and are devoted to the wrong problems. This view is the vanguard of a new, third wave of environmentalism that is taking root in America. It began in the 1980 s among farmers, homeowners, and others who were upset by the growing cost of regulations that didn't seem to bring any measurable benefit. Corporate executives have argued along these lines for years, but have gone unheeded, even during twelve years of Republican administration. Richard J. Mahoney, chairman and chief executive of Monsanto, the chemical company, said the nation may start listening to industry now. "People want to know, even with the environment, what we are getting for our money," he said (Yakutchik).

\section{The Betty Crocker Syllogism}

Another symptom that the quest for environmental correctness is out of control is the all-too-frequent occurrence of environmental false alarms. These incidents leave the "experts" responding to journalists' questions concerning what might have happened if the white powder spill that caused police to close the freeway had involved something more toxic than self-rising flour. In February and July of 1993, the California Highway Patrol closed mile-long portions of I-580 during peak traffic hours while experts were brought in to assay mysterious white powder that appeared on the roadway. In both cases, police rerouted commuters for hours while investigators traveled-by ambulance, with sirens and flashing lights, and by helicopter-to analyze the material. The first case involved a one-pound bag of tile grout (the empty bag was found in an oleander bush on the center divider by a fire fighter about the time the 
assessment team arrived in their white, hostile-environment suits and respirators). The more recent spill consisted of approximately ten pounds of cake flour. Each incident involved emergency responses from police, fire, and transportation officials as well as hazardous waste disposal crews, at a cost to taxpayers of many thousands of dollars. Who decides to call in the experts?

\section{Abandoning the Myth of Expertise}

Four dissimilar tragedies-Challenger, Chernobyl, Bhopal, and the Exxon Valdez-have become "cognitive markers" representing the dangers of high technology and permanently damaging the public's faith in experts. In the past, experts-using probakilistic risk calculations-determined what was and was not an acceptable level of risk. In this technocratic, elitist environment, the experts told the people what was best for them. The follow-on to the failed acceptablerisk approach was risk-benefit analysis. This type of analysis quantified benefits as well as risks, but placed monetary value on the quality of life and on human life itself. After risk-benefit analysis came risk perception-a process by which people's concerns are elicited - on the experts' questionnaire. Although more

sensitive than risk-benefit analysis, there is still no active role for non-experts; the results still depend on whether the experts ask the right questions (Otway). The Risk Communication Study Group at the Los Alamos National Laboratory (Durbin, et al.) cautions all stakeholders in risk assessment situations to beware of "dueling experts" - subject matter experts who hold (and argue) opposing points of view on a subject, based on virtually the same statistical data. 
The U.S. Supreme Court recently gave federal judges wider latitude to decide whether scientific data is reliable enough to be admitted into evidence in federal trials. Ruling unanimously in a California birth-defects case, the court threw out a strict rule that federal courts have used for decades in deciding whether to let scientific testimony be presented to a jury. Trial judges may consider a variety of factors to "ensure that any and all scientific testimony or evidence admitted is not only relevant, but reliable," Justice Harry A. Blackmun wrote for the court. "Proposed testimony must be supported by appropriate validation-i.e., 'good grounds,' based on what is known." Historically, as technologies have developed, risks associated with them have been addressed by government regulations, usually promulgated by government officials working together with industry experts-not the public at risk.

The U.S. Department of Energy (DOE), for example, regulates the inventory of hazardous materials that can be used or stored at its contractors' sites. Under DOE Safety Analysis Regulation 5480.23, health physicists employed by DOE are responsible for determining the toxicity of substances based on the most current available health data. After considering the contractor location (e.g., proximity to population centers), possible accident scenarios, potential routes of entry of the various toxic substances, and usually based on the most conservative (e.g., the "most sensitive person") model, each substance is defined as low, medium, or high (Category 3, 2, or 1, respectively) risk.

The agency then issues a site-specific compliance document that specifies the quantities of hazardous, radioactive, and mixed wastes that facility may store. 
Because the penalties for violating DOE orders are very stringent, and because violations often incite significant criticism from the public, site managers consider the orders inviolable and, in fact, tend to overcomply. Depending on the particular facility's record of compliance and other factors, DOE does afford some flexibility. Under the terms of DOE Guidance 1027, for example, facilities may increase their inventories of certain radioactive isotopes by applying a calculation that compensates for that facility's remote location, climate, safety record, and history of compliance (Van Warmerdam).

The disadvantage of this system is that local site managers become so focused on compliance issues, they no longer give much thought to their own value systems, perceptions of risk, or to the actual materials involved. Health physicists at a remote location thousands of miles away dictate the rules; local site managers comply. Once codified, thousands of rusty barrels of radioactive and toxic wastes lose their identities as potentially deadly substances and are reduced to theoretical, statistical units.

\section{The Uncertainty Factor}

McKone and Bogen (1991) state the case for uncertainty in no uncertain terms: "Overall uncertainty results from variability in natural systems and human behavior and our ignorance about them." Because the complexity of new technologies increases the uncertainties of risk, there is more room for honest disagreement among experts. The statistical and mathematical models used by scientists such as McKone and Bogen to mitigate uncertainties in health-risk assessment are extremely complicated and quickly exceed the comprehension of 
most well-educated individuals. Industry officials argue that epidemiological statistics are the only valid hedge against uncertainty. But because it takes decades to compile epidemiological statistics, potentially risky technologies must either proceed unchecked or rely on mathematical models until empirical data becomes available-at the expense of unwitting human epidemiology subjects.

Because of the sheer number of unverifiable probabilities inherent in new technologies, "fact" tends to be conditioned by political, economic, and ethical influences. Corporations lobby government to ensure that regulations do not interfere with profits. Technology sponsors, upon discovering a new technology that might benefit society-and their stockholders' portfolios-are eager to sing its praises and, equally -and innocently-eager to downplay potential risk. Such optimism arises from technological sponsors' genuine belief in themselves, in science, and in their products.

According to Baker (referring to an article by B. Fischoff), risk communicators themselves may be sources of additional risk. "If the risk communication is inappropriate or fails to communicate the message it was intended to, it may result in worrisome stress and consequently, poor health outcomes. The impairment to the immune systems of too much worry may be more dangerous than the risks associated with the hazard being worried about."

Technology sponsors have opportunities to make or break their projects, to improve the efficiency and openness of policy making, and to raise the general public's level of knowledge about technical issues that effect their lives. We would like to believe that science provides all the answers to the risks of new 
technology, but the truth is that because of this arrogance, humans tend to make judgment errors precisely where we expect to be infallible. Experts have too often demonstrated their lack of profound knowledge in their fields of expertise (Otway).

The real experts in the area of risk value assessment are the people whose lives are affected. To most people, the field of risk assessment is just another alien technology, and the numbers that result from it are as mysterious as the technology in question (Cannel). Many people have become fearful that they need to act directly to protect their own interests in a world they perceive as increasingly dominated by corporate entities and back-room dealings (Martin).

Technology sponsors often approach risk communication from the point of view that the public is simply irrational when dealing with technological risks. In the ideal situation, if everyone were appropriately educated, everyone would perceive risks the same way-in a way consistent with the "expert" perception. This kind of thinking confuses two processes that should be kept separate: first, the responsibility of technology sponsors to keep the public informed of technological risks; and second, the political task of deciding what risks are acceptable, i.e., determining what kind of a technological society we want to live in. According to Thayer, "The task of risk communication isn't just to communicate information; it's to alert people when they ought to be alerted, and to reassure them when they ought to be reassured."

Good science and good public policy require different standards of judgment. No scientific principle can be used to determine how many cases of 
leukemia are worth the cost of a pollution control device or how many miscarriages balance the advantages of the aerial spraying of pesticides.

\section{The Process of Perception}

It is a basic principle of cognitive psychology that perception is a constructive process; external events and messages take on meaning and are accorded significance based on each individual's internal representation of the world (Cohen). This implies that if one is to undertake an understanding of another individual's perceptual and evaluative capabilities, one must have an understanding of that individual's personal and social background. Credibility is enhanced when the message is shown to be accurate and the process by which the information is obtained is perceived as legitimate.

Studies undertaken to determine which technological risks are perceived as the most and least acceptable to people reveal several consistent findings:

- Public perception of risk is substantially different from that of the scientific community.

- Man-made hazards are perceived as less acceptable than those caused by acts of nature.

- Detectable hazards are more acceptable than undetectable ones.

- Risks imposed by others are less acceptable than those assumed voluntarily (e.g., contaminated tap water $v$ s diet soda containing carcinogens.

- Risks that identify specific groups of people at risk are less acceptable than those that seem to occur randomly. 
- Levels of concern increase with uncertainty. The less that is known about a potentially risky technology, even if no specific hazards are known, the less acceptable the technology.

- Catastrophes that occur infrequently but claim many lives at once are less acceptable than hazards that consistently claim more lives, one or two at a time (e.g., in the U. S., major airplane crashes kill an average of 50 people each year but this rate is considered less acceptable than the 113 killed each day in automobile accidents.

- The possibility of accidents that involve irreversible hazards and risk to future generations tops the list of public concerns.

- People rely on the opinions of relatives, co-workers, and friends.

- Risks that the public are least willing to accept are those associated with memorable disasters and those presented by untrustworthy sources.

\section{Different Perspectives}

Technology sponsors often try to create public acceptance of risks by presenting them as inconsequential when compared to other, statistically greater, risks that the public tends to ignore. According to an M.I.T. study, the statistical probability of dying in a plane crash aboard a domestic coast-to-coast commercial airliner is about one in 11 million (Russell). In other words, a person who flies every day is likely to be involved in a fatal crash once every 29,000 years. In 1991, 41,150 Americans died in auto accidents; 49 died in commercial 
airline accidents. Realistically, however, a person who has just seen a report about a fatal plane crash might consider the M.I.T. statistics personally irrelevant.

Although some risk communication experts favor using rational comparison statements to attempt to reassure the public, it is important to select comparisons that do not deviate from quantitative or qualitative similarities. A classic example of an "acceptable risk" statement is the "granite comparison." Common granite contain natural radiation. The amount of radiation in granite buildings like Grand Central Station in New York City exceeds federal standards for nuclear power plants. If Grand Central Station were a nuclear energy plant, it could not be licensed to operate (Bisconti). Comparisons that are guaranteed not to work involve comparing involuntary risks, such as drinking water contaminated by trace levels of a carcinogen, with smoking two cigarettes a day. A smoker who already feels overwhelmed by the negative attention smokers receive may reject the argument.

\section{Risk Communication by Persuasion}

Despite overwhelming agreement among risk communication experts that persuasion and advocacy can easily destroy credibility, some technology sponsors insist on attempting to change public perception of risk by attempting to resolve conflict using scientific persuasion tactics. Persuasion is defined as an attempt to alter attitude or to modify behavior. Besides the fact that attitude and behavior modification are difficult to accomplish—and unreliable-processes, technology sponsors are venturing into potentially unethical territory. Many people are extremely sensitive to the methodology and will resist persuasion if 
they realize that a change in their behavior might serve interests other than their own (Cannel). Skeptical audiences are also sensitive to nuance of speech, gesture, and body language. The perception of inaccuracy, misrepresentation, incompetence, or deceit on the part of technology sponsors can cause the failure of an otherwise worthwhile project.

Keeney and von Winterfeldt, promoting the concept that the product of successful risk communication is the resolution of conflict, propose that the complexities of technological risks should be taught in school. Among the "facts" they recommend teaching are:

- There are no zero-risk solutions.

- Trade-offs are always necessary.

- Uncertainty cannot be avoided.

\section{Smoke and Mirrors}

In opposition to many risk communication experts, Keeney and von Winterfeldt advise that "It may...be necessary to learn from the tricks of advertising agencies and from public relations firms to improve the effectiveness of risk communication. A recent marketing strategy involves the development of "clear" products. Clear cola drinks and clear deodorants are perceived as more healthful, even if the contents are identical to their artificially colored counterparts. What these writers fail to understand is that the public is generally sophisticated enough to recognize those tricks as manipulation (Tuller). Resorting to ad-agency trickery can prejudice the public against the technology at hand, the communicator, and the institution they represent-forever. 
Although it is important for organizations involved in the business of risk assessment communication to institute and sustain a continuing program in the community to maintain a working relationship, it is critical that such a program does not acquire the appearance of a sales pitch. California strategists developed a series of conferences-hosted by the League of Women Voters-to acquaint government officials and citizens with the issue of low-level radioactive waste repositories. The program included field trips to Nevada disposal facilities. Such programs foster better communications because activities inform and empower communities, while enabling the people involved to meet face-to-face in a neutral environment. This kind of strategy, when implemented in an honest effort to inform, moderates the politically fatal us-vs.-them mentality (Coleman).

Bureaucratic policy makers, accustomed to top-down communication styles, fail to engender public support by assuming a paternalistic role; ignoring the influence of local decision makers, relying on scientific persuasion techniques to change public attitudes, disregarding public opinion and risk perception, and viewing public reaction as hysterical. Intellectual limitations and the need to reduce anxiety often lead to denial that risk exists and to unrealistic oversimplifications of essentially complex problems (Coleman).

Risk communicators often make the mistake of trying to "convert" their strongest opponent. Instead, Mary I. Woodell, a senior vice-president at the public relations firm Hill and Knowlton in New York City, suggests that it is smarter to identify and work with what is probably the larger group of undecided people (Thayer). 


\section{Information Without Persuasion}

In this era of the public's disenchantment with technical experts, a new paradigm for risk communication is beginning to emerge. Instead of trying to persuade people to accept policies or technologies and the risks they imply, successful risk communicators will tell people how they can avoid or mitigate risks, and provide information that will help them form their own opinions. It is important to address the needs of the audience-the primary recipient of risksas well as the needs of the technology sponsor.

A starting point for establishing effective communication is to acknowledge the limits of expertise and to remain open to discussion of technological uncertainties, alternative interpretations, and the benefits the communicator hopes to achieve. Several organizations and risk communication experts have developed do and don't lists for communicators-ranging from ethically sensitive to outrageously manipulative. The most comprehensive, down-to-earth, and practical contribution I have found in the literature is a report released by the National Research Council in 1988, Improving Risk Communication. For the reader intent on understanding the principles of risk communication, this document is an excellent condensation of the important concepts in the published literature, combined with a sober commentary based on the investigation conducted by a committee of distinguished experts in the field. It is not a "cookbook" for risk communicators, but it does offer problems and solutions to many procedural and ethical issues. 
Although my research has led me to be skeptical of the cookbook approach to risk communication because no single approach works in every instance, I am aware that some readers will benefit by having a list of strategiesnot rules-to review for guidance. Therefore, I have condensed the following list of communication objectives from the many that appear in the literature. The list is by no means complete, and it is not intended to be. It is provided solely as guidance to attain a mind-set conducive to successful risk communication. The communicator may use none, some, or all of the strategies; the list will be successful if it induces a state of mind that encourages the communicator to be consistently compassionate and honest:

- Find out what people are concerned about and answer in those terms. The risk communicator should be prepared to state clearly, and according to the present state of knowledge, whether the tap water is safe to drink.

- Avoid technical jargon, circumlocution, and bureaucratic language.

- Cast the results of risk analyses in terms that make sense to lay people.

- Relate risk assessment information to the audience's personal experience.

- Provide graphical material that people can easily understand.

- State your real communications objectives explicitly and in a straightforward manner. 
- Use a direct, trustworthy, non-controversial approach-empathy, honesty, and direct, non-technical language. Credibility is easy to lose, and nearly impossible to restore.

- Improve interaction with information transmitters, e.g., science writers, community leaders, and well-informed members of the media.

- Do not evade.

- Do not hide behind bureaucratic arguments.

- Do not second-guess your audience.

- Never, never lie.

\section{Involve the Stakeholder}

Without an understanding of how the public thinks and makes decisions about technological risks, "well-intended policies may be ineffective or even counterproductive" (Covello). For risk communication to be successful, "stakeholder" groups must be involved early. Their values and concerns must be taken seriously. The effort must be one of joint problem solving. Try to identify new solutions based on value inputs from all stakeholders. Empowering the public can be the determining factor in a technology sponsor's success or failure. Quoting A. Bandura (1977), Conger and Kanungo make a case for being honest and forthright with the public:

"The strength of peoples' conviction in their own effectiveness is likely to affect whether they would even try to cope with given 
situations...they get involved in activities and behave assuredly when they judge themselves capable of handling situations that would otherwise be intimidating."

Technology sponsors need to acknowledge that the non-technical audience possesses a different (not inferior) set of knowledge, experience, and expertise that complements theirs. Citizens in a democracy have the right to expect that their commurications to each other, and to the experts, are treated as equally important as communications from the experts. Because technical experts rely heavily on qualitative statistical models to determine prospective risks, the validity of risk as perceived by the scientist may be no more accurate when extrapolated to a non-simulated population than that of the well-informed lay person (Baker).

Public policy researchers and risk communication experts agree that involvement and support of local government leaders and key citizens is critical. Disregard for the influence of local leaders can disenfranchise important segments of a community. Citizens want to feel empowered in decision-making processes in their communities. A more people-centered risk analysis implies a more professional role for risk communicators-a role in which loyalty is owed first to a professional code of ethics, then to the employer (Coleman).

From the perspective of basic democratic ethics, the goal of risk communications should be to expose-not resolve-the value differences within society. It is important to maintain a commitment to people, as well as to technology. Risk communicators must keep in mind cultural differences 
(e.g., opposition to nuclear energy or water fluoridation), and that different stakeholders have different views about what constitutes a risk or threat.

Risk communicators must avoid the arrogance of prejudging what citizens ought to think, feel, or do. Instead, they should confine themselves to explaining the relevant information as clearly as they can and should measure their success by what facts the audience has learned (Sandman ). The perception of risk is just as important as the reality of any given risk (Baker, Russell). Risks that kill people are often not the same risks that frighten and anger them. If dissemination of risk information is to be ethical, it must help people deal with the risks as they perceive them. People will behave based on the information they have, how they perceive the risk, what their attitudes about technology are, and the context under which these components come together. Reaching consensus is not a legitimate goal for risk communicators. The ethical risk communicator will provide dependable, unbiased information that addresses real uncertainties that people have about how to decide which risks they will choose to accept.

\section{Informed Consent}

Throughout the risk communication literature, one common observation recurs: acceptability of technological risk seems likely to coincide with voluntariness. Some individuals are more likely than others to be chronic risk takers, but even non risk takers will take occasional risks within their personal realm of voluntariness. To confirm this phenomenon, one needs only to observe the behavior of people-removing the technological variable-who choose to accept serious risks of a non-technological nature. 
The recent catastrophic fire storm that consumed hundreds of million-dollar homes on thousands of acres in Southern California is a sobering example. Although arson is presumed to have been the cause, Southern California is a reclaimed desert; the arid Malibu hills have burned before and they will burn again, but new homes will be built there before the ink is dry on the insurance checks.

A study in the journal Science (January 8,1993 ) found that during the past 500 years, five earthquakes measuring 7 to 8.3 on the Richter scale have ruptured the San Bernardino Mountains segment of the San Andreas fault. The study revealed that big quakes happen somewhere on the southern San Andreas about every 100 years (instead of every 132 years as previously believed). "It has been 135 years since the last one," said U. S. Geological Survey geologist Tom Fumal, principal author of the study. Fumal predicts a seismic "disaster is going to happen within the lifetime of most people living in S uthern California."

The quakes happened in 1857,1812 , and roug hly in 1700,1610 , and 1470 , according to studies of breaks in buried layers of gravel and peat. Previous studies have found that three of those quakes ruptured the Mojave segment of the fault, the part closest to Los Angeles. Kerry Sieh, a California Institute of Technology geologist who reviewed the study said, "I don't think it makes things worse" than the already high risk of a big quake. Richard Eisner, of the California Office of Emergency Services, said the public "shouldn't be distracted by the debates among scientists." The Federal Emergency Management Agency (FEMA) estimates that a quake measuring 7.5 to 8 or more could kill up to 14,000 people 
and hospitalize another 55,000 , but people who want to live in Southern California refuse to be concerned.

Another example of human beings oblivious to risk is occurring on the "Big Island," Hawaii. Beginning in January 1983, the Kilauea volcano has erupted in 52 episodes. Lava flows destroyed the ancient village of Kalapana. Those whose homes were spared remained; others rebuilt nearby -on the new lava. They are being joined by newcomers who are willing to risk investment in an area scientists say will be inundated again, either by Kilauea or the larger Mauna Loa volcano, which last erupted in 1984. "For many of these people, the love of the land outweighs the dangers. It's an acceptable risk," said Harry Kim, Hawaii County Civil Defense administrator. There is no way of knowing when the eruption will end; earlier eruptions have been known to have lasted as long as 100 years, the last one from 1823 to 1924.

The lava flows have destroyed more than 200 homes and buildings and dozens of archaeological and historical sites, disrupted agriculture, and decimated native plants and animal habitats. Acid rain from volcanic gases and atmospheric moisture damages forests and fresh water sources. Volcanic haze called "vog" causes pollution and possible respiratory problems. "It's so pretty when it's happening," said geologist Christina Heliker of the U. S. Geological Survey's Hawaiian Volcano Observatory. "When you come back, everything has been destroyed."

Effective, ethical risk communication is a two-way process of mutual education. According to Thomas Mann, "A great truth is a truth whose opposite 
is also a great truth" (Otway). The greatest obstacles to effective risk communication involve the perception of technology sponsors to the public, the perception of the public to technology sponsors, and misunderstandings among different groups, e.g., government agencies, special interest groups, etc., over definitions and motivations.

Technology sponsors tend to express perception of risk as a balanceaveraging costs, risks, and benefits across society. Members of the public are more concerned with tangible issues-like whether the water is safe to drink and the air healthful to breathe. Agencies and their analysts offer statistics that seem remote to individuals. The media reinforces this by publishing stories that reflect individual risks dramatically. Analysts see the quantifiable aspects; lay people think in terms of their personal fears and qualitative issues (Keeney). The use of technical and bureaucratic language may be appropriate for producing the analyses, but the results should be reported in language that is easily understood by the public. For example, ground water contaminants should not be communicated only in PPB (parts per billion); such results are only fully comprehended by scientists. The implications of contaminant levels should also be expressed in potential health threats to individuals.

Risk communicators often overstate their cases by presenting the worstpossible-case scenario that might occur if their project is not approved. For example, Keeney and von Winterfeldt, addressing the unachievability of "zero risk" when defending a nuclear power plant, conclude that in the absence of the nuclear plant, less electricity would be available, so people would have to 
conserve. Then they serve up the knockout punch: "Conserving means better insulation in houses, which results in worse indoor air quality." Instead of frightening people with worst-case scenarios, it is desirable to present a menu of risk indicators, so individuals may evaluate those indicators that are relevant to their personal experience. For example, the relative risks of alternative modes of transportation depend on whether one examines fatalities per passenger mile, per hour of exposure, or per trip.

\section{News Media Complications}

Because technology sponsors have traditionally taken a paternalistic approach to disseminating risk information, a number of illogical-and often unethical-practices have evolved. The perceived inability of lay people to understand technical information has resulted in a dependence on the media to translate and transmit information. The media, often lacking scientific qualifications to accurately interpret the data, tends to over-dramatize issues. This has resulted in the public's perception of remoteness from the technology sponsors. The untranslated transmission of idiosyncratic and technical jargon has led to a media preoccupation with the concept of "hidden agendas." The public is left with the feeling that the technology sponsors have hidden motives, which results in a loss of public trust and credibility. When government regulatory agencies step in to referee disagreements between technology sponsors and the public, the result is often ridiculous misinterpretation and irrational overregulation (Keeney). 


\section{Ethical Issues}

Technical communicators have often criticized the assumptions that science-and the application of scientific methodology-are objective and valuefree, and that technical writing needs only to be impersonal and transparent-to avoid imposing value on facts. In theory, technology sponsors and technical writers should explain technology clearly and without condescension; proponents of technical initiatives should make cogent presentations to the public early - before technical concerns can be overshadowed by ideological polarization (Martin).

We would like to believe that technical information, acquired by the conscientious application of scientific methodology, conveyed by applying the principles of effective and efficient communication, and grounded in a firm understanding of professional ethics, could be consistently, systematically, and confidently communicated. For two reasons, this model, unfortunately, breaks down the moment it is removed from the vacuum of rhetorical theory and exposed to real-world applications.

\section{The Rhetorical Model Breaks Down}

The first reason is that because writing and language are closely connected with invention (innovation), they do more than merely transmit work that has already been completed (LeFevre). According to W. John Coletta, “Every description of a thing or 'object' is an assertion or 'proposition' about that thing; there is no purely objective description." Michael Foucault supports this concept 
when he suggests that descriptions are actually further removed from the object: "In the same way that a 'proposition' actively proposes something about a representation, a representation is itself a re-representation of the object."

The second reason is that because technical communicators are employees, and employees are paid to render services to employers to further the goals of institutions, technical writing is-first and foremost-a rhetorical instrument of organizational and bureaucratic rationality. For employers, the essence of the usefulness of technical writing "...lies in the fact that it is capable of giving a rational, 'scientific' mantle to agendas that are always in some measure political, and that it gives the illusion of objectivity to what are always and inevitably interpretations" (Coletta).

In the complex world of real organizations, trade-offs and judgment calls conflict with textbook rhetoric, which does not usually consider the nature of business and the business of human nature. This conflict is a function of the incompatibility of two contradictory claims: (1) that the technical writer is urged to communicate objectively, clearly, directly, and explicitly; and (2) that the technical writer is an agent of the employer, and as such owes a fiduciary allegiance to the employer in terms of serving the employer's political interests.

As this paper goes to press, my employer's political interests are taking an abrupt turn. Last year, the third-largest budget line item at Lawrence Livermore National Laboratory was $\$ 75.8$ million for environmental rleanup related to the U.S. Navy's activities on the Lab's property 50 years ago. The latest risk assessment on what was to be a 50-year, $\$ 105$ million "Superfund" ground water 
cleanup states that in the worst-case scenario, the Lab's ground water pollution, if not cleaned up, "could lead to three cases of cancer per thousand Livermore residents...(but) only if residents were drinking two liters of water a day out of wells at the Lab's perimeter for 70 years." A more realistic study put cancer cases at "more like one in a million." Because of Congress' mandate to cut spending, what was once a high-priority task has been reduced to "a lot of work that quite frankly would be better if you just left it alone" (Weisman).

The rhetorical models taught in technical writing courses usually fail to reflect the reality that as employees, most technical communicators are hired to help employers achieve practical business objectives, such as promoting products, improving efficiency, or increasing sales. In most work environments, political and bureaucratic ideology informs the rhetorical choices that technical communicators make.

\section{Corporate World Protocol}

Dr. Cezar M. Ornatowski, an assistant professor of rhetoric and technical communication at San Diego State University, suggests that being a technical communications professional not only means being an expert communicator, but being able to apply that knowledge to the "...proper protocol for the corporate world." For example, Ornatowski says, "The technical communicator who writes, "The engine failed the test; shipping it may endanger the lives of innocent passengers' in a technical report, may be [rhetorically correct and] ethically wellmeaning, but the report would never survive the review cycle." Ornatowski 
believes that corporate protocol should be taught as a component of any course in technical communication.

Because of the inevitable ethical conflicts that arise when a technical communicator must serve two masters (and walk the subtle line between political prudence and necessary disclosure), the rhetorical choice often results in uneasy compromise. Such rhetorical accommodation (i.e., selective emphasis, understatement, or outright deception) leads to communicative irresponsibility, which has contributed directly to such communication catastrophes as the Three Mile Island nuclear accident and the Challenger disaster.

In his investigation of the events that occurred during the 24 hours preceding the Challenger accident, Patrick Moore documents a series of communication compromises-attributed to corporate intimidation - that led to the fateful decision to launch, despite an overwhelming abundance of corroborating technical data and recommendations to scrub the mission. When the Presidential Commission presented its findings to the American public, it named NASA's Marshall Space Flight Center in Huntsville, Alabama as the principal source of the pressure:

"The commission concluded that the Thiokol Management reversed its position and recommended the launch of 51-L (i.e., Challenger), at the urging of Marshall and contrary to the views of its engineers in order to accommodate a major customer" (Moore, quoting United States, Report 1: 104). 
The "major customer" was Marshall Space Flight Center, which supervised Thiokol's contract for the solid rocket boosters. Even former top NASA officials put much of the blame on Marshall:

“Competition between NASA's main space centers also is blamed for the lack of communication, which current and former top NASA officials say fostered suspiciousness that kept other parts of the agency from learning about shuttle problems" (Moore, quoting Fisher).

Thiokol's engineers had repeatedly complained about the scorched O-rings and steadfastly maintained that the boosters would almost certainly fail at the low temperatures under which the launch was scheduled. Because the pressure to launch was so widely distributed, there was no venue for the engineers to appeal. During the ensuing investigation, one Presidential Commission member described the Marshall managers as "unrepentant" and as "arrogant bastards."

All the post-mortem political rhetoric and finger-pointing could not restore the damage that had been done. Despite two and a half decades of scientific research and empirical testing-almost in spite of scientific methodology - seven astronauts perished, billions of dollars were wasted, and the U.S. space program was crippled. As a result, millions of Americans no longer trust science or scientists.

Despite their dedication to science and their allegiance to their country, the people responsible for communicating their knowledge that Challenger could not tolerate being launched at $18^{\circ} \mathrm{F}$-caved in to bureaucratic intimidation and 
corporate ideology. Those individuals, as certain they were of the risk, and aware of the potential for disaster-specifically loss of life-abandoned their deeplyheld convictions and failed to stand up under corporate pressure to reverse their decisions. How can we ask technical writers to violate corporate protocol in matters of much less significance? According to Moore, such a position-no doubt realistic-can be equated to "throwing in the towel on ethics, because it contains few provisions for action outside bureaucratic control and outside simply serving the corporate interests that pay the bills." But without scientific methodology - and the resulting unreliable and conflicting conclusions-we have no foundation upon which to begin to understand the nature of the ethical conflicts we are certain to encounter. Without awareness of professional ethics, technical communicators "are nothing but hired guns" (Moore).

Technical writers, in the context of employee-employer interaction, will find little opportunity to apply scientific methodology in the conduct of practical, routine communications tasks. Without a thorough understanding, however, of the role of scientific methodology in developing the technical information that writers communicate, in concert with a working knowledge of professional ethics, we lack the capacity to analyze the rhetorical trade-offs and bargains we must make. The first step toward resolving this dilemma is to teach a more substantive, sophisticated, and practical notion of ethics than the simplistic avoidance of blatant dishonesty. 


\section{Conflicting Methodologies}

Scientific representation of probability has suffered a serious loss of credibility as a result of the media coverage of high profile technological disasters. The acceptability of any given risk can change based on new information or on the interdependence of one risky activity on another.

The search for a cure for cancer has resulted in a diverse array of specializations in the field of cancer research. One such subdiscipline involves assessing the probability of acquiring cancer from the myriad possible sources. A spinoff of that research that is directly related to the field of risk communication is determining the acceptability of cancer risks.

Historically, risk acceptability has been expressed by numerical representations, e.g., individual lifetime risk in excess of "background" exposure. Recently, however, in an effort to make the statistics more valid, certain qualitative factors have been added, supported by animal testing and epidemiological data. Nevertheless, failure to consider such factors as responsibility, accountability, social equity, and procedural legitimacy, tend to invalidate the acceptability profiles. Freudenberg argues that through the rhetoric of understatement and selective emphasis, even the most carefully compiled statistics can be manipulated, therefore should not be used to establish government policies on risk:

"Using the highest estimate of risk might mean banning a substance that is in fact moderately safe and imposing economic hardship on manufacturers, workers, and consumers. Using the most optimistic 
assessment on the other hand, might lead to unnecessary illness or death. Even then, the real issue is that what is "safe" for a scientist may not be so for a citizen."

A critical factor that is often overlooked is the reliability of the scientific methodology employed in determining the risk. Because the method selected is either right or wrong, the resulting determination has only a $50 \%$ chance of being correct. Therefore, any statistical information based solely on mathematical models - to the exclusion of empirical validation-has a corresponding $50 \%$ chance of being incorrect. It is only a scientific "best guess." Following are brief descriptions of several methodologies scientists use to arrive at that best guess.

\section{Average Lifetime Exposure}

The probability of a statistically "average" citizen acquiring cancer following average lifetime exposure to the carcinogen benzene might be $1 \times 10^{-6}$. Minimal occupational exposure might be $1 \times 10^{-4}$ and for someone directly involved in manufacturing the substance, $1 \times 10^{-2}$. What is not being considered in most cases, however, are the societal, legal, and political factors.

Risk acceptability must be determined not only on the basis of technological expertise and statistical validity, but also in consideration of such social and ethical issues as the protection of individual rights, the equity of risk-to-benefit distribution, the legitimacy of risk assessment and risk management processes, and most important, awareness of and respect for the public's perception of risk. 


\section{Total Individual Risk}

This methodology is used to determine the level of risk that affects individuals and groups of people in terms of various endogenous and exogenous hazards. It is used to extend hazard rates to specific individuals and populations. Statistical methods commonly used by regulatory agencies and companies to determine risk factors are often misleading. Because of differences in individual background and exposure rates, a randomly selected individual can expect, for example, a real risk of developing cancer from exposure to benzene of $6.3 \times 10^{-5}$ ( 1 in 63,000$)$-not $1 \times 10^{-6}(1$ in a million), as suggested by other widely accepted statistical methods. such as Average Lifetime Exposure.

\section{Attributable Risk}

Attributable risk is the estimate of incremental risk to an individual as a function of the individual's exposure-by some particular cause or source-from among competing sources. For example, if $n$ is a number of sources of risk in an individual, $i$ is a competing source of exposure firing a random stream of biologically effective molecules that cause "hits" in the exposed individual, $t$ is time, and $h$ is a hit or exposure incident. Assuming that the various competing sources of risk do not interfere with one another, then the hazard rate for any source $i$ is $h_{i}(t)$. If the $n$ potential sources of a health effect are statistically independent so that the arrival rate of hits from one source is unaffected by the presence of other sources, then the total risk to the individual at time $t$ from all sources can be represented thus: 


$$
h(t)=h_{i}(t)+\ldots+h_{n}(t) .
$$

According to Ricci, et al., "Since any source $i$ will contribute the fraction $h_{i} / h(t)$ of all expected hits per unit of time at time $t$, this ratio equals the probability that source $i$ contributed the hit that caused the observable health response, and $h_{i}(t)$ is the risk attributable to source $i$ at time $t . "$ The culprit source can be easily found by comparing the ratios of all the competing risks. This is a simplified example of the method commonly used to establish which competing risk is likely to have caused the statistically significant incident. Like most risk assessment models, it is theoretically logical under ideal conditions, but unrealistic because all of the variables that need to be in place for the model to work cannot possibly be predicted with any certainty; hence, methodologies like this one are unreliable for practical applications.

\section{Population Risk}

The currently accepted standard extended statistical method for calculating the distribution of risk to a given population takes into account the differences and similarities among the individuals; e.g., family history of cancer, variety and duration of exposure, age, occupation, gender, and other statistically independent variables. The result is expressed in Total Remaining Life-Years.

This methodology is probably inaccurate because in large populations, various subgroups will have widely variant risk and uncertainty distributions; therefore, the statistical expected number of occurrences per million person-years of exposure will be meaningless to most individuals in the group. 


\section{Attitudes Toward Risk}

The common practice of determining the risk to the "maximally threatened" individual is viewed by McKone and Bogen (1992) as "suspect." For example, an individual whose hazard rate is increased from 0.01 to 0.02 faces a lost life expectancy of about 50 years; whereas, the "maximally exposed individual," whose hazard rate is increased from 0.02 to 0.03 faces only a 17-year reduction in life expectancy.

The practice of placing numerical values on human lives is not unusual, although it is in opposition to the way most people (including most scientists) think about their fellow human beings. One formula, advanced by the Nuclear Regulatory Commission's Advisory Committee on Nuclear Safeguards, is to assign a greater weight to "catastrophic" deaths than to "ordinary" deaths. For example, 1,000 catastrophic deaths (e.g., plane crash, hotel fire) can be considered statistically equal to 4,000 ordinary deaths (e.g., by natural causes).

\section{The Risk Portfolio}

A recent concept that has gained considerable interest among risk assessment experts is advocacy for adopting a portfolio approach to determining risk acceptability. Because risk assessment is based on scientific information that is often highly uncertain and speculative; because new knowledge and changes in attitudes can make formerly acceptable risks no longer acceptable (and vice versa); and because of the possibility that one risky activity can depend on another; the portfolio approach "...provides a new perspective for integrating 
risk acceptability issues into a framework for organizing social risk management decisions" (McKone and Bogen, 1991).

Using the portfolio format involves dividing risk management issues into four categories: known problems, suspected problems, solved problems, and non problems. As new information becomes available, technology sponsors, representatives from potentially imperiled populations, and government regulators can re-order the issues within and among the four categories. Resources are allocated in descending order, based on the prioritized lists. Although conflicts are bound to occur (e.g., should more money be spent to try to solve kuown problems or to investigate suspected ones?). But in terms of acceptability, the categories are clear. Items in the non-problem category are considered entirely acceptable, items in the problems-solved category are provisionally acceptable, etc.

\section{Conclusions}

Before the Three Mile Island accident, the nuclear power industry failed to factor into their risk estimates the potential for operator error. There was not one psychologist with human factors expertise on the staff of the Nuclear Regulatory Commission at that time. It is important for technology sponsors to consult the relevant social and behavioral science literature during early stages of policy or project development.

As important as developing processes for improving risk communicationa nearly unsolvable task because much of the necessary information to predict risk accurately is either unknowable or might not be known for centuries- 
technology sponsors must concentrate on bringing these areas of disputed technology under control. In most cases, the "results" of risk assessment studies are only a scientific best guess. Because the decision to employ the selected analytical methodology is also a best guess, the possibility of the results being accurate are always no better than $50 \%$ because the methodology used to reach the final determination can only be "right" or "wrong." This is not to say that scientists should give up attempting to establish mathematical risk profiles because the methodologies are flawed. If we did not attempt to analyze risk statistics, we would have significantly less information about potentially risky technologies than we now have. Developing statistical analyses and actuarial tables not only brings known risky technologies closer to our understanding, but scientists invariably discover valuable new technological information serendipitously while studying other, often-unrelated disciplines.

Until technology sponsors can pronounce-with a high level of certaintythe risks that technologies pose to individuals and to the environment, risk communicators should be empowered to state only that there is or is not some potential for risk; that is, exactly what the risk is thought to be, how long it will take scientists and researchers to determine the exact risk, and what people can do to reduce (or to protect themselves from) the risk in the meantime. Decisions to move forward with risky technology whose real nature is not well understood, must be made by those most likely to be affected.

Determining risk acceptability must be viewed as a function of a competent decision-making processes. The expertise and discretion of regulatory agencies 
should be balanced against prudent judicial intervention. Similarly, in determining the acceptability of technological risk, regulators and companies must consider social issues and processes-as well as statistics-to arrive at decisions that will be acceptable not only in terms of procedural legitimacy and statistical validity, but which will be socially responsible and individually equitable.

Making socially acceptable decisions about high-risk technologies, and communicating those risks to the people who are most likely to be imperiled, have become significant global issues (Cronkhite). Technology sponsors and risk communicators can either learn to become excellent persuaders, in hopes of being able to mold public perception to suit their technological and political goals, or they can take the ethical high road and help people deal with the risks they must face living in a technological society. 


\section{Works Cited}

Baker, Frank, "Risk Communication About Environmental Hazards," J. Public Health Policy, 41-359 (Autumn 1990).

Bisconti, Ann S. and Robert L. Livingston, Communicating with the Public about Radiation, U. S. Council for Energy Awareness, Washington, D.C. (1992).

Cannel, William and Harry Otway, "Audience Perspectives in the Communication of Technical Risks," Futures, 519-531 (October 1988).

Cohen, Alexander, et al., "Psychology in Health Risk Messages for Workers," J. Occupational Medicine, 27(8) (August 1985).

Coleman, Cynthia-Lou, "What Policy Makers Can Learn from Public Relations Practitioners," Public Relations Quarterly, 26-31 (Winter 1989-90).

Coletta, W. John, "The Ideologically Biased Use of Language in Scientific and Technical Writing," Technical Communications Quarterly, Association of Teachers of Technical Writing, University of Minnesota, St. Paul, MN (Winter 1992).

Conger, Jay A. and Rabindra N. Kanungo, "The Empowerment Process: Integrating Theory and Practice," Academy of Management Review 13(3) 471-482 (1988).

Covello, Vincent, et. al., "Risk Communication: An Assessment of the Literature on Communicating Information about Health, Safety, and Environmental Risks," Draft preliminary report to the Environmental Protection Agency from the Institute for Safety and Systems Management, University of Southern California, Los Angeles, CA (January 1986).

Cronkhite, Gary and Jo R. Liska, The Judgment of Communicant Acceptability, from Persuasion: New Directions in Theory and Research, 101-139 , Roloff, M. E. and G. R. Miller, eds., Sage Annual Reviews of Communication Research, Sage Publications, Beverly Hills, CA (1980).

Durbin, Peggy, Susan Klein, Sheila Molony, Carol Wade, and Linnea Wahl, "Twelve Principal Components of Outrage," Los Alamos National Laboratory Risk Communication Committee (1992). 
Foucault, Michael, "The Ideologically Biased Use of Language in Scientific and Technical Writing," Technical Communications Quarterly, Association of Teachers of Technical Writing, University of Minnesota, St. Paul, MN (Winter 1992).

Freudenberg, Nicholas, Not in Our Backyards, Monthly Review Press, NY (1984).

Gardner, David, "Report to the LLNL Technical Information Department's Risk Communication Committee," oral presentation, Lawrence Livermore National Laboratory (February 1992).

"Howe, Kenneth, "Magnetic Fields Stir New Health Fears," San Francisco (CA) Chronicle, 1 (March 8, 1993).

Keeney, Ralph L. and Detlof von Winterfeldt, "Improving Risk Communication," Risk Analysis, 6(4) 417-423, Society for Risk Communication (1986).

LeFevre, Karen Burke, Invention as a Social Act, Conference on College Composition and Communication, Southern Illinois University Press, Carbondale, IL (1987).

Martin, Wanda, "Public Policy and Professional Communication: Perils and Possibilities," IEEE Transactions on Professional Communication, 34(4), (December 1991).

McKone, Thomas E. and Kenneth T. Bogen, "Predicting the Uncertainties in Risk Assessment," J. Environmental Science and Technology, Vol. 25, American Chemical Society (1991).

McKone, Thomas E. and Kenneth T. Bogen, "Uncertainties in Health-Risk Assessment: An Integrated Case Study Based on Tetrachloroethylene in California Groundwater," J. Regulatory Toxicology and Pharmacology, 15, 86-103 (1992).

Mendelsohn, Mort, Hiroshima Institute, "Long-term Effects of Low-Level Radiation," Radiation Quarterly, quoted in Newsline, Lawrence Livermore National Laboratory (March 1993).

Milwaukee Journal, as reported in Alameda (CA) Newspaper Group, Tri-Valley Herald, A-7 (January 27, 1993).

"Moore, Patrick, "Intimidation and Communication, A Case Study of the Challenger Accident," J. Bus. and Tech. Comm, 6(4), 403-437 (October 1992). 
New York Times, "Environmental Program Gone Awry," excerpted in Alameda (CA) Newspaper Group Tri-Valley Herald, A-1 (March 21, 1993).

Ornatowski, Cezar M., "Public Policy and Professional Communication: Perils and Possibilities," IEEE Transactions on Professional Communication, 34(4), (December 1991).

Otway, Harry, "Experts, Risk Communications, and Democracy," Risk Analysis, 7(2), 125-129, Society for Risk Analysis (1987).

Ricci, Paolo F., Louis Anthony Cox, Jr., and John P. Dwyer, "Acceptable Cancer Risks: Probabilities and Beyond," J. Air and Waste Management (October 1989).

Russell, Christine, “What, Me Worry?” American Health, 45-50 (June 1990).

Sandman, Peter M., et al., "Public Response to the Risk from Geological Radon," J. Communication, 37(3) 93-108, (Summer 1987).

Thayer, Ann M., "Alar Controversy Mirrors Differences in Risk Perceptions," CEEN Northeast News Bureau, 7-14 (August 28, 1989).

Tuller, David, "Clear Products Sell Healthy Image," San Francisco Chronicle, 1 (March 8, 1993).

Van Warmerdam, Charlotte, Manager, Hazardous Waste Management Team, Environmental Restoration Division, Lawrence Livermore National Laboratory, Livermore, CA (personal communication, August 18, 1993).

Weisman, Jonathan, "Clamping Costs of Cleanup," Alameda (CA) Newspaper Group, Tri-Valley Herald, 1 (October 27, 1993).

Yakutchik, Maryalice, "Is My Electric Blanket Killing Me?" U. S. Weekly Magazine, 12, Gannett Co., Inc. (January 1-3, 1993).

Seven Cardinal Rules of Risk Communication (OPA-87-020), U. S. Environmental Protection Agency, Washington D.C. (April 1988). 


\section{Works Consulted}

Davis, Bob, What Price Safety? Risk Analysis Measures Need for Regulation But It's No Science, Wall Street Journal (8/6/92).

Dunkel, Jeffrey R. and Debra A. Prybia, Why Community Relations is Not Public Relations, 46-472, Public Participation, NUS Corporation, Gaithersburg, MD, (November 1985).

Johnston, Ron and Philip Gummett, eds., Directing Technology, St. Martin's Press, NY (1979).

Lundgren, Regina, "Communicating Risk," Pacific Northwest Laboratory, workshop held at Lawrence Livermore National Laboratory, Livermore, CA (August 31, 1992).

Mumpower, Jeryl. L., Lottery Games and Risky Technologies: Communications About LowProbability/High-Consequence Events, 231-235, Society for Risk Analysis (1988).

Piasecki, Bruce and Peter Asmus, (foreword by Jean-Michel Cousteau), In Search of Environmental Excellence, Simon and Schuster, NY (1990).

Schmertz, Herb, Good-bye to the Low Profile (The art of creative confrontation), Little, Brown \& Co., Boston (1986).

Slovic, Paul, "Perception of Risk," Articles, 280-285, Decision Research, Eugene, OR (April 1987).

Surrey, John, ed., The Urban Transportation of Irradiated Fuel, St. Martin's Press, NY (1984).

Risk Communication Manual for Electric Utilities, Electric Power Research Institute (EPRI EN-7314 Vols 1 and 2), Palo Alto, CA (June 1991).

Communicating Environmental Risks: A Guide to Practical Evaluations, United States Environmental Protection Agency (EPA 230-01-91-001) (December 1990). 
$1 !$
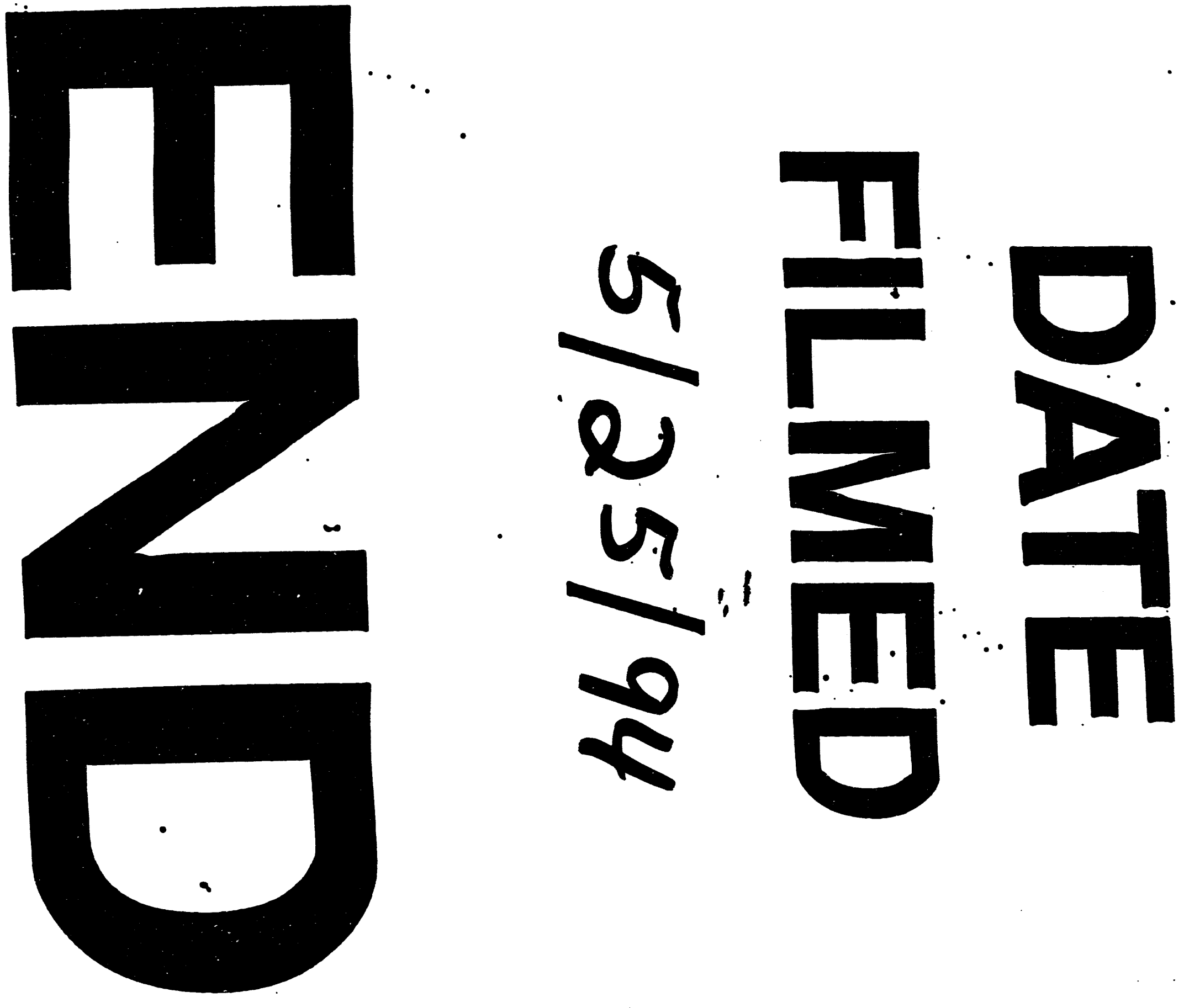
